\title{
Does Intra-Operative Administration of Tranexamic Acid Increases the Chance of Tubeless Percutaneous Nephrolithotomy
}

\author{
Ankur Jhanwar ${ }^{\star}$, Nilesh Kumar Jain ${ }^{2}$, Nitin Lashkary ${ }^{3}$, Sanjay Hada1, Lalit Bhardwaj ${ }^{1}$, Ankur Bansal ${ }^{4}$ \\ 1Senior Resident, 2Professor, ${ }^{3}$ Assistant Professor, \\ Department of Urology, Government Medical College, Kota, Rajasthan, India. \\ ${ }^{4}$ Senior Resident, Department of Urology, SGPGI, Lucknow, Uttar Pradesh, India.
}

\begin{abstract}
Objective: To observe the outcome of intra-operative administration of tranexamic acid (TXA) in percutaneous nephrolithotomy (PCNL).

Patients and Methods: We retrospectively review the records of 198 patients from August 2014 to April 2016. Patients were divided into two groups on the basis of tranexamic acid. Group $A(n=96)$ were given intra operative tranexamic acid and group $B(n=102)$ did not receive any tranexamic acid.

Results: The mean age in group $A$ was $34.28 \pm 10.38$ and in group $B$ was $34.9 \pm 10.76$ years ( $p=0.772$ ), mean stone size in group $A$ and $B$ were $1.97 \pm 0.52,2.01 \pm 2.40 \mathrm{cms}$ respectively, $\mathrm{p}=0.912)$. The mean operative time in group $A$ and $B$ were $44 \pm 4.2,52.55 \pm 16$ minutes respectively, $p=0.0001$ ), mean hemoglobin $(\mathrm{g} / \mathrm{dl})$ change was $0.98 \pm 0.26$ and $1.6 \pm 0.42$ in group $A$ and $B$ respectively $(p=0.001)$. Mean hospital stay was $69.61 \pm 11.5$ and $78.2 \pm 10.6$ hours in group $A$ and $B$ respectively $(p=0.0002)$. Twelve patients $(12.5 \%)$ in group $A$ and $93(91.1 \%)$ patients in group $B$ had nephrostomy tube placement $(p=0.0001)$.
\end{abstract}

\section{INTRODUCTION}

In the current era, the goal of stone treatment is to use a minimally invasive, yet effective modality associated with low morbidity. Percutaneous nephrolithomy (PCNL) introduced in 1976', considered a gold standard treatment for simple and complex renal calculi with good success rate ${ }^{2}$. Urologists are now moving toward tubeless PCNL, as it is fascinating and appealing to the surgeon and patient as well. It was realised that the purpose of tube is only to maintain the adequate drainage of kidney and therefore, the concept tubeless approach of PCNL has been evolved in 1997.

Previously the concept behind placing the nephrostomy tube is to provide hemostasis along the tract, avoid urinary extravasation and maintain adequate drainage of the kidney ${ }^{3}$. This approach was appreciated all around and has been utilised to improve patient postoperative care like pain and length of hospital stay ${ }^{4}$. The use of antifibrinolytic agents such as tranexamic acid have been described in the literature in various surgical procedures including PCNL, as bleeding is the most unpredictable and dreaded complication of PCNL and can lead to significant
Conclusions: Intraoperative administration of tranexamic acid increases the chances of tubeless percutaneous nephrolithotomy.

Key words: Tranexamic acid, Tubeless, Percutaneous nephrolithotomy.

\section{*Correspondence to:}

Dr Ankur Jhanwar, 668 A, RK Puram

Kota, Rajasthan, India.

\section{Article History:}

Received: 27-08-2016, Revised: 14-09-2016, Accepted: 05-10-2016

\begin{tabular}{|l|c|}
\hline \multicolumn{2}{|c|}{ Access this article online } \\
\hline $\begin{array}{l}\text { Website: } \\
\text { www.ijmrp.com }\end{array}$ & Quick Response code \\
\hline DOI: & \\
10.21276/ijmrp.2016.2.6.021 & \\
\hline
\end{tabular}

morbidity 5 . Tranexamic acid is a low molecular weight competitive inhibitor of plasminogen activation and a non-competitive inhibitor of plasmin at higher concentration.

\section{PATIENTS AND METHODS}

We retrospectively review the records of 198 patients (112 males, 86 females) who had undergone PCNL in the department of Urology of a tertiary care centre in north India from August 2014 to April 2016. Patients were divided into two groups. Intra-operative administration of injection tranexamic acid was the basis of division. Group A ( $n=96$ ) consists of patients who had been administered $1 \mathrm{gm}$ of intravenous injection tranexamic acid during PCNL and group B $(n=102)$ consists of patients without tranexamic acid.

Records revealed that none of the 198 patients included in the study had solitary functioning kidney, serum creatinine greater than $1.5 \mathrm{mg} / \mathrm{dl}$, bleeding diasthesis. All procedures were performed by well experienced urologist under spinal/general anaesthesia with standard PCNL technique. 


\section{TECHNIQUE OF PCNL}

Under spinal/general anaesthesia, a $5 \mathrm{Fr}$ ureteric catheter was negotiated beyond the calculus under cystoscopic and fluoroscopic guidance. After ureteric catheter placement, patient made to lie in prone position. Percutaneous tract access was obtained under fluoroscopic guidance using a diamond tip 18guage puncture needle. A hydrophilic guide wire was either passed antegradely into ureter or coiled into pelvicalyceal system, over which tract dilatations were done upto $28 \mathrm{Fr}$ (24-28 Fr) using Alken serial metal dilators and an Amplatz sheath was placed into system. Stones were fragmented using pneumatic lithoclast. Intraoperative stone clearance was checked using fluoroscopy. Placement of nephrostomy tube was decided by operating surgeons based on intra-operative conditions (bleeding/pleural violation/significant residual). Tubeless procedure was completed by placing double $\mathrm{J}$ stent antegradely only.

The post-operative treatment protocol was similar in both groups. Hemoglobin drop was measured as the difference between 24 hours preoperative and 24 hours postoperatively hemoglobin level. Intraoperative and postoperative factors like, total operative time, hemoglobin drop, stone clearance rate, length of stay in hospital, VAS pain score (recorded immediately post-surgery, on post-operative day 1 and 2, and any adverse effects of tranexamic acid were recorded. Check X-ray and Ultrasound of KUB region was performed on postoperative day 2 to look for any residual stone fragments. The nephrostomy tube was removed accordingly in group B patients. Double $\mathrm{J}$ stent was removed after 2 weeks in both groups. Success was defined as complete stone clearance or the presence of residual fragments smaller than $4 \mathrm{~mm}$.

\section{STATISTICAL ANALYSIS}

Continuous data are given as mean \pm SD while discrete (categorical) are presented in percentages. The categorical variables were compared by chi-square $\left(X^{2}\right)$ test. The continuous outcomes were compared by using unpaired t-test. A $p$ value $<0.05$ is considered statistically significant. All analyses were performed by using SPSS 16.0 version (Chicago, Inc., USA).

Table 1: Baseline demographic and clinical data of patients.

\begin{tabular}{lccc}
\hline Baseline variables & Tranexamic acid group A $(\mathrm{n}=96)$ & Group B $(\mathrm{n}=102)$ & p- value \\
\hline Mean + SD age (years) & $34.28 \pm 10.38$ & $34.9 \pm 10.76$ & 0.7 \\
Male & 54 & 58 & \\
Female & 42 & 44 & 0.3 \\
Mean BMl $\left(\mathrm{Kg} / \mathrm{m}^{2}\right)$ & $22.7 \pm 2.64$ & $23.22 \pm 2.40$ & 0.9 \\
Mean stone size (cms) & $1.97 \pm 0.52$ & $2.01 \pm 2.40$ & \\
Laterality & & & 0.7 \\
Right & 47 & 54 & 0.7 \\
Left & 49 & 48 & 1 \\
Stone location & & & 1 \\
Upper & 30 & 32 & 1 \\
Middle & 18 & 19 & 1 \\
Lower Calyx & 19 & 21 & \\
Pelvic & 29 & 30 & 1 \\
Puncture & & & 1 \\
Single & 94 & 99 & $\mathrm{NA}$ \\
Multiple & 2 & 3 & \\
Previous intervention & Nil & Nil & \\
\hline
\end{tabular}

Table 2: Perioperative data of both groups

\begin{tabular}{lccc}
\hline Perioperative & Group A $(\mathbf{n}=\mathbf{9 6})$ & Group B $(\mathbf{n}=\mathbf{1 0 2})$ & p value \\
\hline Mean Hb change (g/d)) & $0.98 \pm 0.26$ & $1.4 \pm 0.42$ & 0.0001 \\
Mean operative time(mins) & $44 \pm 4.2$ & $52.5 \pm 5.16$ & 0.0001 \\
With tube & 12 & 93 & 0.0001 \\
Tubeless & 84 & 9 & \\
Mean VAS( pain) & $3.42 \pm 1.2$ & $4.88 \pm 1.4$ & 0.0001 \\
Mean hospital stay (hours) & $69.61 \pm 11.5$ & $78.2 \pm 10.6$ & 0.0002 \\
Clearance rate $(\mathbf{n})(\%)$ & $91(95 \%)$ & $90(88 \%)$ & 0.8 \\
Auxillary Procedures & $4(4.1 \%)$ & $12(11.9 \%)$ & 0.2 \\
Blood transfusion & $6(6.3 \%)$ & $15(14.8 \%)$ & 0.3 \\
Clot colic & $3(3.12 \%)$ & 0 & 0.2 \\
Fever $\geq 38.5^{\circ} \mathrm{C}$ & $6(6.3 \%)$ & $6(7.6 \%)$ & 1 \\
Complication related to tranexamic acid & 0 & - & $\mathrm{NA}$ \\
\hline
\end{tabular}




\section{RESULTS}

Baseline patient's clinical and demographic characteristics were comparable in both groups (Table-1). There was no statistically significant difference between both groups regarding age, gender, mean stone size, laterality of stone, BMI, number of puncture done and history of previous intervention for stone disease.(Table2) Records of 198 patients (112 males, 86 females) were analysed. Group A includes 96 patients and group B includes 102 patients. The mean age in group $A$ was $34.28 \pm 10.38$ and in group $B$ was $34.9 \pm 10.76$ years $(p=0.772)$, mean stone size in group $A$ and $B$ were $1.97 \pm 0.52,2.01 \pm 2.40 \mathrm{cms}$ respectively, $p=0.912$ ). The mean operative time in group $A$ and $B$ were $44 \pm 4.2, \quad 52.55 \pm 16$ minutes respectively, $p=0.0001$ ), mean hemoglobin $(\mathrm{g} / \mathrm{dl})$ change in group $A$ was $0.98 \pm 0.26$ and $1.4 \pm 0.42$ in group $B(p=0.001)$. Mean length of hospital stay (LOS) was $69.61 \pm 11.5$ hours in group $A$ and $78.2 \pm 10.6$ hours in group $B(p=0.0002)$. Twelve patients $(12.5 \%)$ in group $A$ and $93(91.1 \%)$ patients in group $B$ had nephrostomy tube placement $(p=0.0001)$. Stone clearance rate was in group A was $95.64 \%$ and $88.32 \%$ in group B. The Visual analogue pain scale (VAS) score was significantly lower in group $A$ patients as compared to group $B$ ( $3.42 \pm 1.2$ versus $4.88 \pm 1.4)(p=0.0001)$. Six patients $(6.25 \%)$ in group $A$ and 15 patients $(14.8 \%)$ in group $B$ required blood transfusion, 6 patients $(6.25 \%)$ in group $A$ and $6(7.7 \%)$ in group $B$ had fever $\left(\geq 38.5^{\circ} \mathrm{C}\right)$.

\section{DISCUSSION}

In current era of minimal invasive endoscopic surgery, the aim of stone disease surgery is to achieve complete stone free status with less morbidity. PCNL was introduced in 1976, with time it has emerged as a safe and less morbid procedure for large and complex renal calculi6 as compared to open surgery for renal stone. The most important aspect of percutaneous nephrolithotomy is to establish optimal access to the calyx of interest. The procedure gained importance and become the treatment of choice for renal calculi due to its shorter operative time, decreased blood transfusion rate, analgesics requirement, speedy recovery when compared with open surgery ${ }^{7,8}$. In terms of cost-effectiveness this procedure is cost effective when compared with ESWL and RIRS. Review of literature reveals evidences which indicate that tranexamic acid is effective in reducing blood loss in various surgeries including cardiac, gynaecological procedures, caesarean section, urological procedures like Trans urethral resection of prostate (TURP) ${ }^{9,12}$. As there is no validated measure for blood loss during PCNL, all attempts are confounded by the use of irrigation fluid which complicates the ability to measure blood loss by traditional means (suction, sponge weight). Post-operative hemoglobin drop is the standard in the literature. Review of data in this study revealed mean hemoglobin drop of $0.98 \pm 0.26$ and $1.4 \pm 0.42 \mathrm{gm} / \mathrm{dl}$ in group A and B respectively, which is lesser than the study by Stoller ML, Netto $R$ which quotes an average hemoglobin decrease with percutaneous nephrolithotomy ranging from 2.1 to $3.3 \mathrm{gm} / \mathrm{dl}^{13,14}$.

In the present study blood transfused in $6(6.25 \%)$ patients in group A and 15 (14.8\%) patients in group B which is comparable to the study by Michel and Rosette et al, they reported that blood transfusion was required in $5.7 \%$ to $17.5 \%$ of patients who underwent PCNL ${ }^{15,16}$. Similar to other studies in literature, the mean operative time in tranexamic acid group (group A) was
$44 \pm 4.2$, and $52.55 \pm 16$ minutes in group $B$, the shorter operative time in group A might be due to less bleeding which effectively maintain the proper vision throughout the procedure and no time spent in placing the nephrostomy tube. Mean pain score (VAS) was also significantly lower in group A (tranexamic acid) patients as compared to control group $(p=0.001)$. The reason for this seems to shorter operative time and no nephrostomy tube placement. Statistically significant difference was observed in mean length of hospital stay between the groups (69.61 \pm 11.5 hours in group $A$ and $78.2 \pm 10.6$ hours in group $B(p=0.0002)$. This might be due to nephrostomy tube placement and patients discharged after its removal. From this study, it seems that nephrostomy tube increased the length of hospitalisation. Few reports in literature observed the occurrence of thromboembolic events associated with the use of tranexamic acid like deep vein thrombosis, pulmonary embolism or myocardial infarction and ureteral obstruction due to clot formation in patients with upper urinary tract bleeding ${ }^{9-12}$.

Fortunately, none of the patients reviewed in this study had experienced any complications related to tranexamic acid. CRASH-2 trial (Clinical Randomisation of an Antifibrinolytic in Significant Haemorrhage) involving more than 20,000 patients with trauma reported that tranexamic acid significantly reduce mortality due to bleeding without any increase in vaso-occlusive events ${ }^{17}$. Rannikko et al ${ }^{12}$ conducted a study in which they concluded that short-term tranexamic acid (TXA) treatment is effective in reducing the operative blood loss associated with TURP and may lead to better surgical conditions like shorter operative times and lesser irrigating fluid volumes. Similarly, we also observed the need for less volume of irrigating fluid requirement in tranexamic acid group. This might be due to lesser operative time, less bleeding which subsequently increases the vision during the procedure. Although, not statistically significant but stone clearance rate was also higher in group A (tranexamic acid) as compared to group $B(95.6 \% \mathrm{v} / \mathrm{s} 88.32 \%)$. Six patients in group $B$ later required ESWL as an adjunctive procedure. The major limitation of this study was its retrospective nature and relatively small sample size.

\section{CONCLUSIONS}

From this study we conclude that, intraoperative administration of tranexamic acid decreases the blood loss and increases the chances of tubeless PCNL. However, a prospective randomized study is required.

\section{REFERENCES}

1. Fernstrom I, Johansson B: Percutaneous pyelolithotomy. A new extraction technique. Scand J Urol Nephrol. 1976; 10: 257-9.

2. Preminger GM, Assimos DG, Lingeman JE Nakada SY, Pearle MS, Wolf JS : Chapter1: AUA guideline on management of staghorn calculi: diagnosis and treatment recommendations: J Urol2005; 173: 1991.

3. Etemadian M, Soleimani MJ et al: Does bleeding during percutaneous nephrolithotomy necessitate keeping the nephrostomy tube? A randomized controlled clinical trial: Urol J. 2011 Winter; 8(1):21-6.

4. Isac W, Rizkala $E$ et al:Tubeless percutaneous nephrolithotomy: outcomes with expanded indications: Int Braz J Urol. 2014 Mar-Apr;40(2):204-11. 
5. Ker K, Edwards P, Perel $P$ et al: Effect of tranexamic acid on surgical bleeding: systematic review and cumulative metaanalysis. BMJ 2012; 344: e3054.

6. Santosh Kumar, Muninder Singh Randhava et al: Tranexamic acid reduces blood loss during percutaneous nephrolithotomy: a prospective randomized controlled study: J urol. Vol 189,17571761,May2013.

7. Feng MI, Tamaddon K, Mikhail A, Kaptein JS, Bellman GC: Prospective randomized study of various techniques of percutaneous nephrolithotomy. Urology 2001; 58: 345-50.

8. Bellman GC, Davidoff R, Candela J, Gerspach J, Kurtz S, Stout L: Tubeless percutaneous renal surgery. J Urol. 1997; 157: 157882.

9. Rahman Z, Hoque R, Ali A, Rahman M, Rahman MS: Blood conservation strategies for reducing peri-operative blood loss in open heart surgery. Mymensingh Med J 2011; 20: 45

10. Celebi N, Celebioglu B, Selcuk M, Canbay O, Karagoz AH, Aypar $\mathrm{U}$. The role of antifibrinolytic agents in gynecologic cancer surgery. Saudi Med J 2006; 27: 637.

11. Gungorduk K, Yıldırım G, Asıcıoglu O, Gungorduk OC, Sudolmus S, Ark C: Efficacy of intravenous tranexamic acid in reducing blood loss after elective cesarean section: a prospective, randomized, double-blind, placebo-controlled study. Am J Perinatol 2011; 28:233.

12. Rannikko A, Petas A, Taari K: Tranexamic acid in control of primary hemorrhage during transurethral prostatectomy. Urology 2004; 64: 955.

13. Stoller ML, Wolf JS Jr, St Lezin MA: Estimated blood loss and transfusion rates associated with percutaneous nephrolithotomy. J Urol 1994; 152: 1977.
14. Netto R, Lemos GC,Palma PC et al: Staghorn calculi: percutaneous versus anatrophic nephrolithotomy. Eur Urol 1988; 15: 9 .

15. Michel MS, Trojan L, Rassweiler JJ: Complications in percutaneous nephrolithotomy. Eur Urol 2007; 51: 899.

16. de la Rosette J, Assimos D, Desai M, Gutierrez J, Lingeman J, Scarpa R, Tefekli A: The Clinical Research Office of the Endourological Society Percutaneous Nephrolithotomy Global Study: indications, complications, and outcomes in 5803 patients. J Endourol 2011; 25: 11

17. Shakur H, Roberts I, Bautista R et al: Effect of tranexamic acid on death, vascular occlusive events, and blood transfusion in trauma patients with significant hemorrahge (CRASH-2):a randomised, placebo-controlled trial. Lancet 2010; 376:23.

\section{Source of Support: Nil. Conflict of Interest: None Declared.}

Copyright: (c) the author(s) and publisher. IJMRP is an official publication of Ibn Sina Academy of Medieval Medicine \& Sciences, registered in 2001 under Indian Trusts Act, 1882.

This is an open access article distributed under the terms of the Creative Commons Attribution Non-commercial License, which permits unrestricted non-commercial use, distribution, and reproduction in any medium, provided the original work is properly cited.

Cite this article as: Ankur Jhanwar, Nilesh Kumar Jain, Nitin Lashkary, Sanjay Hada, Lalit Bhardwaj, Ankur Bansal. Does IntraOperative Administration of Tranexamic Acid Increases the Chance of Tubeless Percutaneous Nephrolithotomy. Int J Med Res Prof. 2016; 2(6):109-12. DOI:10.21276/ijmrp.2016.2.6.021 